\title{
Changes in left ventricular global and regional longitudinal strain during right ventricular pacing
}

Background: LV strain and functions may be altered by Right ventricular apical pacing (RVAP). Right ventricular Septal pacing (RVSP) might be a better alternative. The detrimental effect of RV pacing may be mediated by regional LV impairment.

Objectives: Our study aimed to demonstrate the short term impacts of right ventricular (RV) apical and septal pacing on Left ventricular (LV) regional and global longitudinal strain (GLS) in patients with preserved ejection fraction (EF).

Methods: 62 patients indicated for permanent pacemaker implantation and preserved LV systolic function were included. Dual chamber pacemakers were implanted in all patients. Patients were divided into 2 groups according to RV lead position: group $A(R V A P, n=32$ ) and group $B(R V S P, n=$ 30). Patients were examined at baseline and after 6 months of implantation for $L V$ systolic functions, global and regional strain by echocardiography and 2D speckle tracking echocardiography.

Results: Paced-QRS duration was significantly shorter in group B compared to group A patients ( $P$ value 0.02 ). Regarding ventricular strain, there were no statistically significant difference between both groups at baseline measurements in comparisons of GLS, relative apical longitudinal strain (rALS) and regional longitudinal strain (RLS) (P value of $>0.05$ ). In contrast there was statistically significant difference between both groups appeared in results of GLS (P value of 0.01 ) at 6 months. In addition, regional longitudinal strain in septal, apical and rALS were affected after 6 months with $P$ value of $0.02,0.03$ and 0.03 respectively.

Conclusion: RVAP appears to worsen global longitudinal strain more than RVSP, and the resultant decrease in apical strain is most correlated region to decrease in GLS.

Submitted: 09 January 2016; Accepted: 24 February 2016; Published online: 27 February 2016

Keywords: Left Ventricular - Strain; Right ventricular - Pacing

RVA created heterogeneous LV contraction, which resulted in deteriorated LV longitudinal contraction. RVS could be a better pacing alternative in terms of less LV dyssynchrony and better longitudinal function compared to RVA [1]. To avoid the LV dysfunction in patients with preserved LV function after the procedure of RVA, RV septal pacing (RVS) is reported to be one of the alternative pacing methods to shorten the paced-QRS width and to attenuate mechanical asynchrony [2]. In a review of 14 randomized studies, Shimony et al. found that right ventricular mid-septal pacing (RVMSP) is associated with a better left ventricular ejection fraction (LVEF) during follow-up, compared with right ventricular apical pacing (RVAP) [3].

The physiological rationale behind pacing the septum rather than the apex is based on initiating the ventricular depolarization in
Alaa Solaiman Algazzar ${ }^{1 *}$ Azza Ali Katta', Kahled Said Ahmed", Nasima Mohamed Elkenany ${ }^{2}$ \& Maher Abdelaleem Ebrahim ${ }^{1}$ 'Cardiology Department, National Heart Institute, Egypt

${ }^{2}$ Cardiology Department, Faculty of Medicine, Al-Azhar University, Egypt *Author for correspondence: Tel.: 01148145561

goodminds@hotmail.com 
the RV septal wall, across the base of the mitral septal papillary muscle, where the first activation vector normally starts [1-4]. Two-dimensional speckle tracking echocardiography (STE) allows detailed evaluation of LV mechanics, including LV mechanical dyssynchrony, LV strain, and LV torsion [5-7]. Myocardial strain may have the potential to identify reduced exercise capacity and poor prognosis at an early disease stage when traditional parameters fail $[8,9]$.

The purpose of our study was to compare shortterm effects of right ventricular (RV) apical and septal pacing on Left ventricular (LV) global and regional longitudinal strain in patients with preserved ejection fraction $(\mathrm{EF})$.

\section{Subjects and Methods}

A total of 62 patients, who are indicated for elective permanent dual chamber pacemaker implantation according to current guidelines (class I), were included from May 2103 to August 2015. Adult patients with age less than 75 years with preserved ejection fraction were enrolled in the study after 6 months of implantation if they have more than $60 \%$ pacing dependence. Patients were excluded if they had: reversible causes for AV block, patients with documented chronic heart dysrhythmias (slow AF), Patients with poor echo window, patients with previous coronary artery disease detected by evidence of $L V$ regional wall motion abnormalities at the echocardiogram or pathological Q waves in electrocardiogram, acute coronary syndrome and/or unsTable angina; within 3 months of a myocardial infarction, coronary bypass surgery or a valve replacement, complex congenital heart disease, hypertrophic obstructive cardiomyopathy, severe mitral regurgitation, haemodynamically significant aortic stenosis, previous implanted pacemaker or ICD, post-AV junctional ablation and patients with terminal co-morbidities such as end stage malignancy, end stage renal or liver diseases.

After written informed consent patients were divided into 2 groups according to RV lead position; group A: RV apical pacing $(\mathrm{n}=32)$ and group $\mathrm{B}: \mathrm{RV}$ septal pacing $(n=30)$. Appropriate positioning of the electrode was confirmed fluoroscopically at the time of the pacemaker implantation, before the baseline visit.

Documentation of lead position was acquired in each patient using 3 standard projections: anteriorposterior, $40^{\circ}$ left anterior oblique (LAO $40^{\circ}$ ), and $40^{\circ}$ right anterior oblique (RAO $40^{\circ}$ ) views referring to the method described by Mond et al. [10]. The LAO fluoroscopic view appears to be the most desirable method to determine RV septal positioning $[11,12]$.

Patients were subjected to full history taking with history of the medications, complete general and local examination of the heart, chest and abdomen [12] lead ECG was done after programming pacemaker at heart rate of 90 beat / minute (at time of doing ECG only) and duration of the QRS complex included the measurement of the time interval between the emission of the pacemaker spike and the end of the QRS complex (milliseconds (ms)).

Study participants underwent a transthoracic echocardiographic examination in the left lateral recumbent position using a commercial ultrasound scanner (Philips EPIQ 7, Philips healthcare, 3000 Minuteman Road, Andover, Ma 0180 USA) with electronic ultrasonic transducer (X5-1).

Both groups were examined at baseline and after 6 months by conventional echocardiography and 2D speckle tracking for:

- Calculations of morphometric parameters were done in accordance with the recommendations of American Society of Echocardiography [11]. The biplane Simpson's rule was used for calculation of global LV ejection fraction (EF).

- Pulsed tissue Doppler imaging (TDI) was used to obtain septal and lateral velocities for both $\mathrm{E}$ and $\mathrm{S}$ waves.

- Two-dimensional speckle tracking were performed to obtain longitudinal strain (LS) using apical (4, 2-chamber, and long axis views). Three consecutive cardiac cycles of each view were acquired during a breath hold at end-expiration. All the images were obtained at a frame rate of 50 frames to 80 frames per second. Timing of aortic valve closure was assessed looking at the aortic valve motion in the long-axis apical view and guided by ECG. All studies were digitally recorded and transferred to a dedicated workstation for further analysis.

Strain values from all segments were averaged to obtain a global LS value [13]. Also, the strain values all segments at the three levels: basal, mid and apical segments of the LV were averaged to obtain three 'regional' LS values. Strain values for each wall at all levels were obtained and averaged to obtain the average strain of the septal, lateral, inferior and anterior walls. The apex-to-base gradient in regional LS was examined using absolute strain values as well as a relative apical LS calculated as: Relative apical LS=Average apical LS/(average basal LS + Average mid LS) [14].

\section{Statistical analysis}

The collected data was tabulated and statistically analyzed using SPSS version 22.0 for Windows (SPSS Inc, Chicago, IL, USA). Normal distribution of data was checked by Kolmogorov- Smirnov test. Categorical data are summarized as frequencies and percentages. 
Comparisons between the groups were performed using the unpaired Student $t$ test. Comparisons within the group were performed using the paired Student t test. A probability value of 0.05 was considered statistically significant. multiple linear regression analysis were performed to provide regression analysis and analysis of variance for one dependent variable as GLS levels at 6 months to QRS width, pacing percentage and regional strain parameters at baseline.

\section{Results}

\section{Baseline characteristics}

No significant difference between both groups regarding baseline characteristics and medications as outlined in Table 1.

\section{Echocardiographic characteristics}

In our study there was no statistically significant difference in left ventricular EF, septal and lateral $\mathrm{E}$ and $\mathrm{S}$ waves by pulsed tissue.

Doppler in both groups (P value $>0.05$ ) as shown in Table 2. After 6 months, the paced-QRS width was significantly shorter in group B compared to group A patients ( $\mathrm{P}$ value 0.02 ) as outlined in Table 2.

\section{Left ventricular global and regional strain}

Regarding ventricular strain, our results showed no statistically significant difference between both groups at baseline measurements in comparisons of global longitudinal strain (GLS), relative apical longitudinal strain (rALS) and regional longitudinal strain (RLS) (P value of $>0.05$ ). In contrast there was statistically significant difference between both groups appeared in results of GLS (P value of 0.01) at 6 months as shown in Table 3 and Figure 1. In addition, regional longitudinal strain in septal, apical and rALS were affected after 6 months with $P$ value of $0.02,0.03$ and 0.03 respectively as shown in Table 3. Figure 2 shows changes of apical longitudinal strain and GLS before and 6 months after RVA pacing.

\section{Correlation}

Figure 3 shows positive relationship between apical strain at baseline and GLS at 6 months with (R 0.622 and $\mathrm{P}$ value of 0.001$)$. Other regional strains failed to show any significant correlation with GLS after 6 months except QRS width (R 0.352 and $\mathrm{P}$ value of 0.03 ) as shown in Table 4. On multivariable linear regression analysis, apical longitudinal strain at baseline $(\mathrm{b}=0.471, \mathrm{p}<0.001)$ and $\mathrm{QRS}$ duration $(\mathrm{b}=0.257, \mathrm{p}$ $<0.049$ ) were independently related with GLS.

\section{Discussion}

Two-dimensional speckle tracking echocardiography is a feasible echocardiographic technique with an angle independency and high frame rate, which is capable of obtaining any directional strain. According to previous reports, the assessment of global systolic function by speckle tracking-based GLS was superior to the standard variables such as LV ejection fraction and wall motion score index for the prediction of outcome in patients undergoing echocardiography with good reproducibility [15-18]. We evaluated the LV global and regional longitudinal strain using a speckle tracking-based strain during RV pacing, addressing the hypothesis that GLS and regional strain during systole was more deteriorated in right ventricular apical (RVA)

\begin{tabular}{|c|c|c|c|}
\hline Variables & Group A $(n=32)$ & Group B $(n=30)$ & P value \\
\hline Age in years $(m+S D)$ & $61.1 \pm 7.5$ & $58.3 \pm 7.1$ & 0.18 \\
\hline Body mass index $(\mathrm{m}+\mathrm{SD})$ & $26.59 \pm 3.19$ & $26.35 \pm 3.78$ & 0.78 \\
\hline Male $n(\%)$ & $6(30)$ & 19(63.3) & 0.31 \\
\hline Female $\mathrm{n}(\%)$ & $14(70)$ & $11(36.7)$ & \\
\hline Smoking n(\%) & $6(30)$ & $15(50)$ & 0.07 \\
\hline Diabetes n(\%) & $4(20)$ & $5(16.7)$ & 0.67 \\
\hline Hypertension n(\%) & $10(50)$ & $16(53.3)$ & 0.79 \\
\hline Dyslipidemia n(\%) & $4(12.5)$ & $4(13.3)$ & 0.92 \\
\hline ACE inhibitors n(\%) & $11(34.3)$ & $8(26.6)$ & 0.51 \\
\hline Beta blockers n(\%) & $4(12.5)$ & $6(20)$ & 0.42 \\
\hline Calcium channel blockers n(\%) & $4(12.5)$ & 1(3) & 0.18 \\
\hline Diuretics n(\%) & $9(28.1)$ & $14(46.6)$ & 0.13 \\
\hline Insulin n(\%) & $4(12.5)$ & 1(3) & 0.18 \\
\hline Metformin $\mathrm{n}(\%)$ & $5(15.6)$ & $3(10)$ & 0.5 \\
\hline Gliclazide n(\%) & $2(6)$ & 0 & 0.16 \\
\hline Glimpride $n(\%)$ & $1(3.1)$ & $4(13.3)$ & 0.14 \\
\hline Statin $n(\%)$ & $4(12.5)$ & $4(13.3)$ & 0.9 \\
\hline
\end{tabular}

\begin{tabular}{|c|c|c|c|c|c|}
\hline & & Group & Mean & SD & P value \\
\hline \multirow[b]{6}{*}{ Baseline } & \multirow{2}{*}{ Ejection fraction (\%) } & Group A & 59.06 & 4.37 & \multirow[b]{2}{*}{0.12} \\
\hline & & Group B & 61.4 & 4.88 & \\
\hline & \multirow{2}{*}{ Septal E by TD (cm/s) } & Group A & 10.9 & 1.55 & \multirow[b]{2}{*}{0.64} \\
\hline & & Group B & 11.17 & 2.84 & \\
\hline & \multirow{2}{*}{ lateral E by TD (cm/s) } & Group A & 12.71 & 1.67 & \multirow[b]{2}{*}{0.09} \\
\hline & & Group B & 13.5 & 19.9 & \\
\hline \multirow{10}{*}{$\begin{array}{l}\text { After } 6 \\
\text { months. }\end{array}$} & \multirow{2}{*}{ QRS duration (ms) } & Group A & 138.68 & 15.23 & \multirow[b]{2}{*}{$0.02^{*}$} \\
\hline & & Group B & 122.23 & 24.97 & \\
\hline & \multirow{2}{*}{ Ejection fraction (\%) } & Group A & 56.65 & 5.36 & \multirow[b]{2}{*}{0.07} \\
\hline & & Group B & 60.36 & 6.21 & \\
\hline & \multirow{2}{*}{ Septal E by TD (cm/s) } & Group A & 10.78 & 1.56 & \multirow[b]{2}{*}{0.75} \\
\hline & & Group B & 10.96 & 2.96 & \\
\hline & \multirow{2}{*}{ lateral E by TD (cm/s) } & Group A & 11.92 & 1.9 & \multirow[b]{2}{*}{0.12} \\
\hline & & Group B & 12.66 & 1.86 & \\
\hline & \multirow{2}{*}{ Pacing percentage (\%) } & Group A & 75.31 & 14.59 & \multirow[b]{2}{*}{0.32} \\
\hline & & Group B & 72.03 & 10.96 & \\
\hline
\end{tabular}

$\mathrm{m}=$ mean, $\mathrm{SD}=$ standard deviation, $\%$ is the percentage within the group; TD=Tissue Doppler imaging, $\mathrm{cm}=$ centimeter, $\mathrm{ms}=$ milliseconds and $\left({ }^{*}\right)$ means significant $\mathrm{P}$ value. 


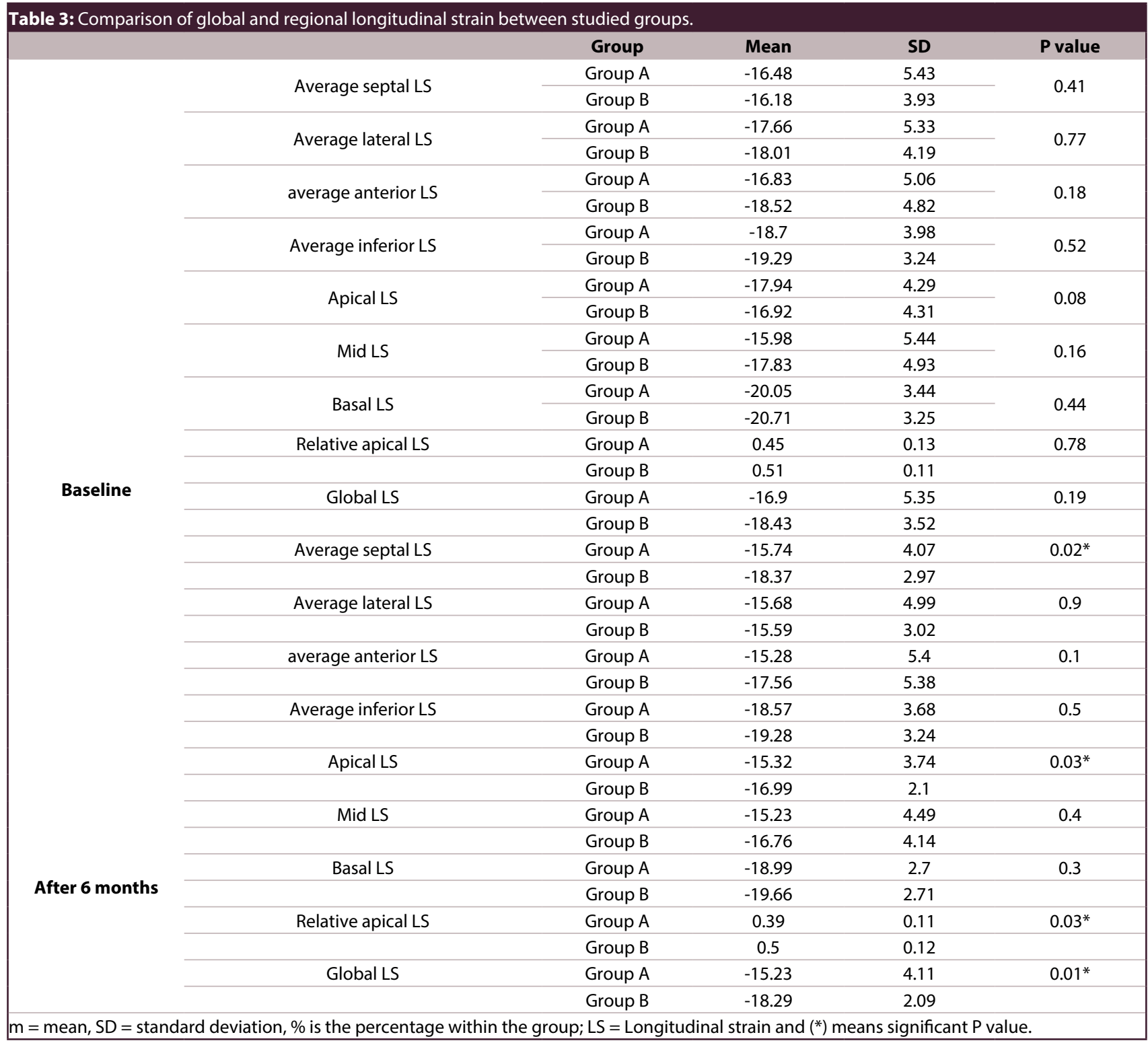

pacing than that in right ventricular septal (RVS) pacing.

In our results, GLS was preserved in RVS lead than RVA lead position mostly as a result of Purkinje fiber recruitment. Impulse conduction using Purkinje fibers would promote depolarization in a more physiological fashion through the rapid conduction of these specialized muscle fibres. Furthermore, it is proposed that RVS lead pacing may assist interand intra-ventricular conduction by recruitment of circumferentially orientated myocardial fibers [19]. In support of these hypotheses this study found that during pacing from the RV mid-septum the QRS complexes became narrower, reflecting a reduction in electrical delay.
Meta-analysis by Shimony et al. concluded that nonRVA pacing generally was not inferior to RVA pacing and that the longer the study period, at least greater than 1 year, the more likely the result would favour nonRVA pacing. A review of individual studies shows that other sources of variation are also important-including duration of follow-up, lead position, percentage pacing, and baseline LV function [20].

In our study we included only patients with preserved EF as baseline LV function is another potentially important determinant of the LV response to pacing. In a previous acute pacing study, RVA pacing in normal LV function produced little in the way of dyssynchrony but as baseline LV function worsened, the amount of dyssynchrony was greater. This would suggest that 


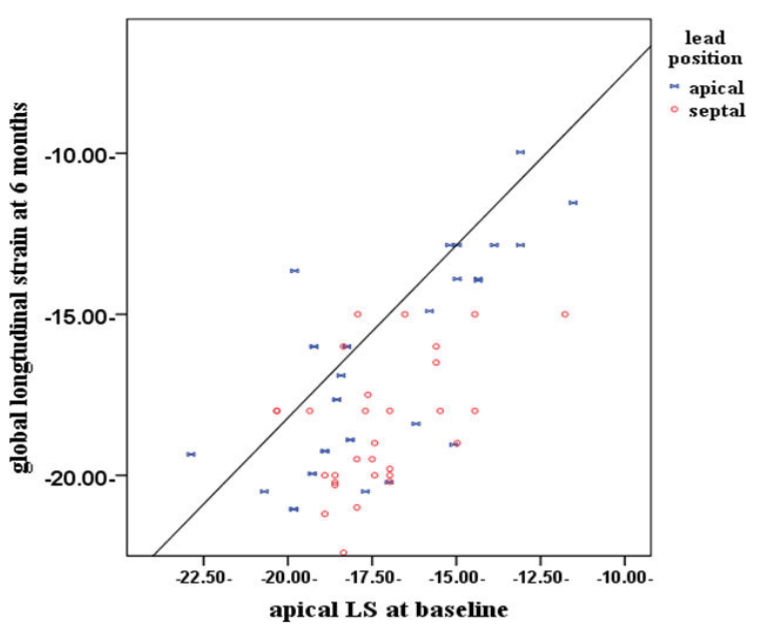

Figure 1: shows Global longitudinal strain (GLS) in both groups at baseline and after 6 months.

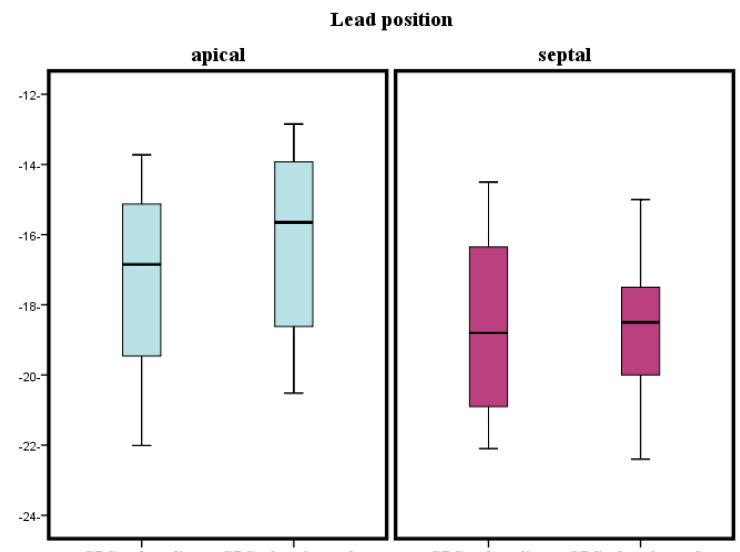

Figure 2: Shows changes of apical longitudinal strain and GLS before and 6 months after RVA pacing. GLS was decreased from -22.7 to -11.7 after 6 months of RVA pacing.

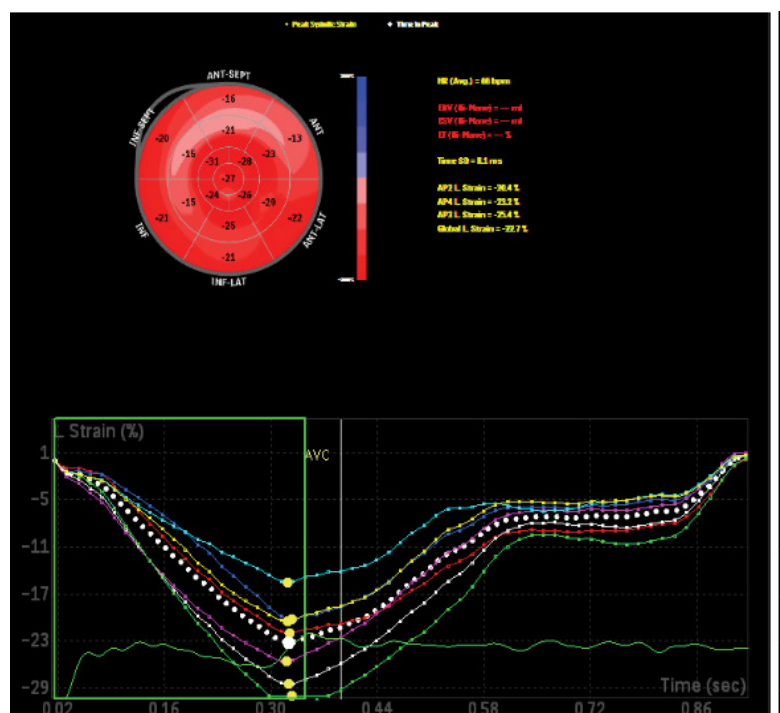

baseline LV function is important in the response to right ventricular pacing [21].

In contrast to our results, the Protect-Pace study showed that pacing from either RVA lead or RVS lead position results in a small but statistically significant reduction in overall LV function over a 2-year period, but RVS pacing does not confer any protective (or detrimental) effect on LV systolic function over RVA pacing. Thus, there is no current indication to change standard pacing practice with regard to RV lead placement, as this remains a safe and effective treatment for a high-degree AV block [22]. But the primary endpoint of this study is the change in EF and Secondary end-points were death and hospitalization for heart failure, atrial fibrillation (AF) burden, changes in brain natriutetic peptide (BNP) levels, 6-minute walk test. They did not use any quantification methods as strain or dyssynchrony. The ejection fraction, derived only from changes to the ventricular lumen, does not necessarily reflect myocardial muscle or sarcomeric shortening. Even if contractility is reduced, compensatory mechanisms (ie, ventricular dilatation, geometry changes) can still assure that stroke volume remains normal at least at rest [23]. Previous studies have suggested that changes in LV function might occur after 12-18 months [24-26].

We found that RVA pacing worsen apical, relative apical and septal regional strain more than RVS pacing. In our study the resultant decrease in apical strain is correlated with GLS. This was the same as Makoto et al., who found that Septal apical strain was significantly lower in RVA than that in non-RVA at baseline and 2 years. Overall, change in GLS for 2 years was significantly correlated with septal apical strain at 2 years

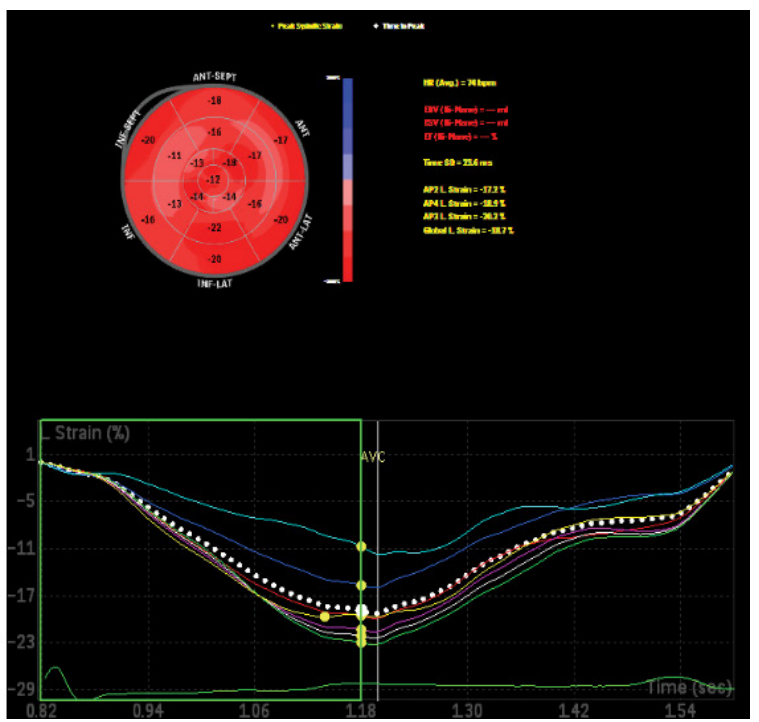

Figure 3: Scatter plot graph showed the relationship between global longitudinal strain (GLS) after 6 months and apical longitudinal strain at baseline $(r=0.622, P 0.001) . L S=$ longitudinal strain. 


\begin{tabular}{|ccc|}
\hline Table 4: Correlation between GLS and different variables at baseline. & & GLS at $\mathbf{~ m o n t h s ~}$ \\
\hline Variables Controlled for lead position & R value & value \\
\hline QRS duration & 0.352 & $0.03^{*}$ \\
\hline Apical LS at base line & 0.622 & $0.001^{*}$ \\
\hline Mid LS at base line & 0.233 & 0.07 \\
\hline basal LS at base line & 0.189 & 0.29 \\
\hline average anterior wall LS at baseline & 0.218 & 0.09 \\
\hline average inferior wall LS at baseline & 0.209 & 0.1 \\
\hline average lateral wall LS at baseline & 0.216 & 0.09 \\
\hline average septa wall LS at baseline & 0.252 & 0.054 \\
\hline GLS=Global longitudinal strain, LS=Longitudinal strain and $\left(^{*}\right)$ means significant P value. & \\
\hline
\end{tabular}

[27]. RVA pacing leads to increasing intra-ventricular dyssynchrony, even though mid-septum lead position was believed to normalize LV dyssynchronization caused by RV pacing [28].

This phenomenon can be explained by altered cardiac mechanics due to lead position. Myocardial fiber orientation in the LV wall is helix like and LV fibers are in 2 opposite directions in subepicardium and subendocardium [29-32]. Contraction of these obliquely oriented fibers creates a twisting motion of the LV. Torsional deformation is determined by the net effect of positive torsional deformation forces developing in the subepicardium and negative torsional deformation forces generated in the subendocardial fibers. The loss of torsion results from the reduction of counterclockwise apical rotation. These severe impairments of apical strain cannot generate sufficient apical rotational movement, which is the main determinant of LV systolic twist [33-34].

It is important to note that measures of regional or segmental function such as myocardial strain may actually reflect 'global' systolic function better than the ejection fraction. Ejection fraction can be determined by both myocardial strain and end-diastolic wall thickness [35]. Several reports have confirmed a significant correlation between LV torsion, apical rotation, strain variables and EF. Apical rotation was demonstrated to be an independent predictor of EF reduction [33-37]. In 2 different studies, healthy subjects were evaluated in sinus rhythm and later with AV synchronous RVA pacing. Acute RVA pacing causes reductions in LV longitudinal strain and twist. So this should be next step in our analysis $[38,39]$.

From the above mentioned studies we can infer why affection of apical strain is strongly correlated to GLS, and late on affect EF. The recognition of abnormal LV strain patterns may provide longitudinal clues to LV dysfunction in chronically paced patients and potential novel indices of effective CRT interventions to reverse these abnormalities.

\section{Limitations}

We could not evaluate other speckle trackingderived parameters in a circumferential and radial direction. The present analysis focuses on the shortterm impact of right ventricular apical pacing on LV functions and does not provide information about the long-term consequences. However, previous studies have demonstrated acute effect of RVA pacing on GLS [40,41]. We considered GLS as a surrogate to EF. However we should evaluate the effect lead position on apical rotation and LV torsion. We could not fully achieve the blinding of the echocardiographer because the additional lead was visible during examination. Finally, we need a large trial that unify clinical and quantification methods of follow up including understanding cardiac mechanics to evaluate effect of RV lead position.

\section{Conclusion}

RV apical pacing appears to worsen global longitudinal strain more than RV septal pacing, and the resultant decrease in apical strain is most correlated region to decrease in GLS. 
Executive summary

- Background: LV strain and functions may be altered by Right ventricular apical pacing (RVAP). Right ventricular Septal pacing (RVSP) might be a better alternative. The detrimental effect of RV pacing may be mediated by regional LV impairment.

- Objectives: Our study aimed to demonstrate the short term impacts of right ventricular (RV) apical and septal pacing on Left ventricular (LV) regional and global longitudinal strain (GLS) in patients with preserved ejection fraction (EF).

- Methods: 62 patients indicated for permanent pacemaker implantation and preserved LV systolic function were included. Dual chamber pacemakers were implanted in all patients. Patients were divided into 2 groups according to RV lead position: group A (RVAP, $n=32$ ) and group B (RVSP, $n=30)$. Patients were examined at baseline and after 6 months of implantation for LV systolic functions, global and regional strain by echocardiography and 2D speckle tracking echocardiography.

- Results: Paced-QRS duration was significantly shorter in group B compared to group A patients (P value 0.02). Regarding ventricular strain, there were no statistically significant difference between both groups at baseline measurements in comparisons of GLS, relative apical longitudinal strain ( $r A L S)$ and regional longitudinal strain (RLS) ( $P$ value of $>0.05)$. In contrast there was statistically significant difference between both groups appeared in results of GLS ( $P$ value of 0.01 ) at 6 months. In addition, regional longitudinal strain in septal, apical and rALS were affected after 6 months with $P$ value of $0.02,0.03$ and 0.03 respectively.

- Conclusion: RVAP appears to worsen global longitudinal strain more than RVSP, and the resultant decrease in apical strain is most correlated region to decrease in GLS.

\section{References}

1. Inoue $\mathrm{K}$, Okayama $\mathrm{H}$, Nishimura $\mathrm{K}$, et al. Right ventricular septal pacing preserves global left ventricular longitudinal function in comparison with apical pacing: Analysis of speckle tracking echocardiography. Circ. J. 75, 1609-1615 (2011).

2. Cano O, Osca J, Sancho-Tello MJ, et al. Comparison of effectiveness of right ventricular septal pacing versus right ventricular apical pacing. Am. J. Cardiol. 105, 1426-1432 (2010).

3. Shimony A, Eisenberg MJ, Filion KB, Amit G. Beneficial effects of right ventricular non-apical vs. apical pacing: a systematic review and meta-analysis of randomized-controlled trials. Europace. 14, 81-91 (2012).

4. Durrer D, van Dam RT, Freud GE, et al. Total excitation of the isolated human heart. Circulation. 41, 899-912 (1970).

5. Leitman M, P Lysyansky, S Sidenko, et al. Two- dimensional strain-A novel software for real-time quantitative echocardiographic assessment of myocardial function. J. Am. Soc. Echocardiogr. 17, 1021-1029 (2004).

6. Reisner SA, Lysyansky P, Agmon Y, et al. Global longitudinal strain: a novel index of left ventricular systolic function. J. Am. Soc. Echocardiogr. 17, 630-633 (2004).

7. Hasselberg NE, Haugaa KH, Sarvari SI, et al. Left ventricular global longitudinal strain is associated with exercise capacity in failing hearts with preserved and reduced ejection fraction. Eur. Heart. J. Cardiovasc. Imaging. 16, 217-224 (2015).

8. Mondillo S, Galderisi M, Mele D, et al. Echocardiography Study Group of The Italian Society Of Cardiology (Rome, Italy). Speckletracking echocardiography: a new technique for assessing myocardial function. J. Ultrasound. Med. 30, 71-83 (2011).

9. Lang RM, Badano LP, Mor-Avi V, et al. Recommendations for cardiac chamber quantification by echocardiography in adults: an update from the American Society of Echocardiography and the European Association of Cardiovascular Imaging. J. Am. Soc. Echocardiogr. 28, 1-39 (2015).
10. Mond HG, Hillock RJ, Stevenson IH, McGavigan AD. The right ventricular outflow tract: the road to septal pacing. Pacing. Clin. Electrophysiol. 30, $482-491$ (2007).

11. Hillock RJ, Mond HG. Pacing the right ventricular outflow tract septum: time to embrace the future. Europace. 14, 28-35 (2012).

12. Roxana Cristina RIMBAS, Andrei Dumitru MARGULESCU, Calin SILISTE, Dragos VINEREANU. Left Ventricular Strain Analysis Reveals Better Synchrony and Diastolic Function for Septal Versus Apical Right Ventricular Permanent Pacing. Journal of Clinical Medicine. 9, 232-241 (2014).

13. Burns KV, Kaufman CL, Kelly AS, et al. Torsion and dyssynchrony differences between chronically paced and nonpaced heart failure patients. J. Card. Fail. 17, 495-502 (2011).

14. Phelan D, Collier P, Thavendiranathan $\mathrm{P}$, et al. Relative apical sparing of longitudinal strain using two- dimensional speckletracking echocardiography is both sensitive and specific for the diagnosis of cardiac amyloidosis. Heart. 98, 1442-1448 (2012).

15. Stanton T, Leano R, Marwick TH. Prediction of all-cause mortality from global longitudinal speckle strain: comparison with ejection fraction and wall motion scoring. Circ. Cardiovasc. Imaging. 2, 356-364 (2009).

16. Marwick TH, Leano RL, Brown J, et al. Myocardial strain measurement with 2-dimensional speckletracking echocardiography. J. Am. Coll. Cardiol. Img. 2: 80-84 (2009).

17. Shimon A Reisner, Peter Lysyansky, Yoram Agmon, et al. Global Longitudinal Strain: A Novel Index of Left Ventricular Systolic Function. J. Am. Soc. Echocardiogr. 17, 630-633 (2004).

18. Freudenberger RS, Wilson AC, Lawrence-Nelson J, Hare JM, Kostis JB. Myocardial Infarction Data Acquisition System Study Group, Permanent pacing is a risk factor for the development of heart failure. Am. J. Cardiol. 95, 671-674 (2005).

19. Siu CW, Wang M, Zhang XH, Lau CP, Tse HF. Analysis of 
ventricular performance as a function of pacing site and mode. Prog. Cardiovasc. Dis. 51, 171-182 (2008).

20. Shimony A, Eisenberg MJ, Filion KB, Amit G. Beneficial effects of right ventricular non-apical vs. apical pacing: a systematic review and meta-analysis of randomized-controlled trials. Europace. 14, 81-91 (2012).

21. Pastora G, Noventa F, Pioversana P, et al. Left ventricular dyssynchrony resulting from right ventricular apical pacing: relevance of baseline assessment. Pacing. Clin. Electrophysiol. 31, 1456-1462 (2008).

22. Kaye GC, Linker NJ, Marwick TH, et al. Effect of right ventricular pacing lead site on left ventricular function in patients with high-grade atrioventricular block: results of the Protect- Pace study. Eur. Heart. J 36, 856-862 (2015).

23. Blessberger $\mathrm{H}$, Binder $\mathrm{T}$. NON-invasive imaging: Two dimensional speckle tracking echocardiography: basic principles. Heart. 96, 716-722 (2010).

24. Hillock RJ, Mond HG Pacing the right ventricular outflow tract septum: time to embrace the future. Europace. 14, 28-35 (2012).

25. Molina L, Sutton R, Gandoy W, et al. Medium- Term effects of septal and apical pacing in pacemaker dependent patients: a double blind prospective randomized study. Pacing. Clin. Electrophysio. 3, 1-8 (2013).

26. Tse HF, Yu C, Wong KK, et al. Functional abnormalities in patients with permanent right ventricular pacing. The effect of sites of electrical stimulation. J. Am. Coll. Cardiol. 40, 14511458 (2002).

27. Makoto Saito, Kazuaki Negishi, Gerry Kaye, Nick Linker, M Gammage. Thomas Marwick. Effect of right ventricular pacing site on global left ventricular myocardial deformation: role of dyssynchrony and regional function. J. Am. Coll. Cardiol. 63, 12-S (2014).

28. Inoue $\mathrm{K}$, Okayama $\mathrm{H}$, Nishimura $\mathrm{K}$, et al. Right ventricular pacing from the septum avoids the acute exacerbation in left ventricular dyssynchrony and torsional behavior seen with pacing from the apex. J. Am. Soc. Echocardiogr. 23: 195-200 (2010).

29. Hansen DE, Daughters GT, Alderman EL, et al.
Effect of acute human cardiac allograft rejection on left ventricular systolic torsion and diastolic recoil measured by intramyocardial markers. Circulation. 76, 998-1008 (1987).

30. Ingels NB, Hansen DE, Daughters GT, et al. Relation between longitudinal, circumferential, and oblique shortening and torsional deformation in the left ventricle of the transplanted human heart. Circ. Res. 64, 915-927 (1989).

31. Moon MR, Ingels NB, Daughters GT, et al. Alterations in left ventricular twist mechanics with inotropic stimulation and volume loading in human subjects. Circulation. 89, 142-150 (1994).

32. Kroeker CA, Tyberg JV, Beyar R. Effects of ischemia on left ventricular apex rotation. An experimental study in anesthetized dogs. Circulation. 92, 3539-3548 (1995).

33. Garot J, Pascal O, Diébold B, et al. Alterations of systolic left ventricular twist after acute myocardial infarction. Am. J. Physiol. Heart. Circ. Physiol. 282, H357-362 (2002).

34. Mornos C, Rusinaru D, Manolis AJ, et al. The value of a new speckle tracking index including left ventricular global longitudinal strain and torsion in patients with dilated cardiomyopathy. Hellenic. J. Cardiol. 52, 299-306 (2011).

35. David H MacIver, Ismail Adeniran, Henggui Zhang. Left ventricular ejection fraction is determined by both globalmyocardial strain and wall thickness. IJC. Heart. \& Vasculature. 7, 113-118 (2015).

36. Toumanidis ST, Kaladaridou A, Bramos D, et al. Apical rotation as an early indicator of left ventricular systolic dysfunction in acute anterior myocardial infarction: experimental study. Hellenic. J. Cardiol. 54, 264-272 (2013).

37. K Matsuoka, M Nishino, H Kato, et al. Right ventricular apical pacing impairs left ventricular twist as well as synchrony: acute effects of right ventricular apical pacing. J. Am. Soc. Echocardiogr. 22, 914-919 (2009).

38. Tejman-Yarden S, Bratincsak A, Bachner-Hinenzon N, et al. Left Ventricular Mechanical Property Changes During Acute AV Synchronous Right Ventricular Pacing in Children. Pediatr. Cardiol. 37, 106-111 (2015)

39. Delgado V, Tops LF, Trines SA, et al. Acute effects of right ventricular apical pacing on left ventricular synchrony and mechanics. Circ. Arrhythm. Electrophysiol. 2, 135-145 (2009). 